\title{
Effects of nitric oxide on the biological behavior of HepG2 human hepatocellular carcinoma cells
}

\author{
LEI ZHOU, HENG ZHANG and JIE WU \\ Department of Gastroenterology, The Central Hospital of Wuhan, Tongji Medical College, \\ Huazhong University of Science and Technology, Wuhan, Hubei 430014, P.R. China
}

Received December 25, 2014; Accepted February 11, 2016

DOI: $10.3892 /$ etm.2016.3128

\begin{abstract}
Many studies have found the function of nitric oxide (NO) in cancer as a pro-neoplastic vs. an anti-neoplastic effector, but the role of NO in hepatocellular carcinoma (HCC) remains unclear. The present study aimed to investigate the effects of nitric oxide (NO) on the biological behavior of the human hepatocellular carcinoma cell line HepG2. HepG2 cell was cultured in vitro and treated with or without sodium nitroprusside (SNP), a NO donor. Subsequently, we evaluated the effects of NO in cell proliferation, cell cycle, apoptosis, migration and invasion by MTT assay, flow cytometry, wound healing assay and Matrigel invasion assay. We demonstrate that NO significantly inhibited HepG2 cell proliferation by inducing $\mathrm{G}_{0} / \mathrm{G}_{1}$ phase arrest in a dose-dependent manner. In addition, compared to the control group, cells treated with SNP showed obviously higher apoptosis ratios in a dose-dependent manner. Furthermore, we revealed that NO effectively inhibited the ability of migration and invasion of HepG2 cells. Taken together, our results suggested that NO has an important role in the regulation of biological behavior in $\mathrm{HepG} 2$ cells and the potential for use in the prevention and treatment of HCC.
\end{abstract}

\section{Introduction}

Hepatocellular carcinoma (HCC) is one of the most prevalent types of cancer worldwide, accounting for $85-90 \%$ of primary liver cancers (1). In China, there were estimated to be $>390,000$ new cases of HCC during 2012 and 380,000 HCC-related mortalities; in the same year, HCC was the second most common cause of mortality from cancer worldwide, estimated to be responsible for $\sim 740,000$ mortalities (International

Correspondence to: Professor Jie Wu, Department of Gastroenterology, The Central Hospital of Wuhan, Tongji Medical College, Huazhong University of Science and Technology, 26 Shengli Street, Jiangan, Wuhan, Hubei 430014, P.R. China

E-mail: wujie12375@126.com

Key words: sodium nitroprusside, nitric oxide, HepG2 human hepatocellular carcinoma cell
Agency for Research on Cancer: http://www-dep.iarc.fr/) (2). Hepatectomy is the most effective treatment for HCC at present; however, the tumor recurrence rate at 5 years after resection is $\sim 70 \%(3,4)$. As the molecular mechanisms underlying the development and progression of $\mathrm{HCC}$ have not yet been clarified, the identification of HCC-associated molecules may contribute to improvements in the prevention and treatment of HCC.

The nitric oxide synthase (NOS) enzyme, which has neuronal (NOS-1), inducible (NOS-2) and endothelial (NOS-3) isoforms, catalyzes the oxidation of L-arginine to generate nitric oxide (NO), a highly reactive radical that exerts a wide range of biological activities, including smooth muscle relaxation, inhibition of platelet aggregation and neurotransmission (5). The production of excessive quantities of NO by NOS-2 has been implicated in the pathogenesis of various types of human malignant tumors, including breast cancer (6), colon cancer (7), melanoma (8) and lung cancer (9). However, it remains unclear whether NO functions as a pro-neoplastic or anti-neoplastic effector. Our previous study indicated that decreased levels of NO/NOS-2 in liver tissues may partly contribute to the development and metastasis of HCC (10). In the present study, the human hepatocellular carcinoma cell line HepG2 was selected to investigate the effects of exogenous $\mathrm{NO}$ on cell proliferation, cell cycle, apoptosis, migration and invasion.

\section{Materials and methods}

Cell culture. The HepG2 human hepatocellular carcinoma cell line (American Type Culture Collection, Manassas, VA, USA) was cultured in Dulbecco's modified Eagle's medium (DMEM) supplemented with $10 \%$ fetal calf serum (Gibco; Thermo Fisher Scientific, Inc., Waltham, MA, USA) and $1 \%$ penicillin/streptomycin (Wuhan Boster Bio-Engineering Co., Ltd., Wuhan, China) at $37^{\circ} \mathrm{C}$ in a $5 \%$ $\mathrm{CO}_{2}$ incubator.

Measurement of NO production. HepG2 cells were seeded in 6 -well plates at a density of $3 \times 10^{4}$ cells/well in growth medium until they reached a confluence of $80 \%$ and were then exposed to $0,0.5,1.0,1.5$ or $2.0 \mathrm{mM}$ sodium nitroprusside (SNP; Beyotime Institute of Biotechnology, Haimen, China) for $24 \mathrm{~h}$. NO levels were determined by measuring stable NO derivatives 
(total nitrites), in the cell culture supernatant with a commercially available kit according to the manufacturer's protocol (Beyotime Institute of Biotechnology). Briefly, $50 \mu \mathrm{l}$ culture supernatant was mixed with $100 \mu \mathrm{l}$ Griess reagent (Beyotime Institute of Biotechnology, Haimen, China) in a 96-well plate. The absorbance was measured using a 680 model microplate spectrophotometer (Bio-Rad Laboratories, Inc., Hercules, CA, USA) at $540 \mathrm{~nm}$, and nitrite was calculated from a standard curve derived from $\mathrm{NaNO}_{2}(0-100 \mu \mathrm{M})$. Each experiment was performed in triplicate.

Cell viability assay. Cell viability was assessed using a methyl thiazolyl tetrazolium (MTT) conducted with a commercially available kit according to the manufacturer's protocol (Beyotime Institute of Biotechnology). Cells were seeded at a density of $5 \times 10^{3}$ cells/well in 96 -well plates in $10 \%$ fetal calf serum-DMEM overnight to allow attachment. The next day, the wells were washed 3 times with DMEM and the medium was changed to serum-free DMEM. Thereafter, the cells were incubated in $0,0.5,1.0$ or $1.5 \mathrm{mM} \mathrm{SNP}$ for $24 \mathrm{~h}$. Subsequently, $10 \mu \mathrm{l}$ MTT solution $(5.0 \mathrm{mg} / \mathrm{ml})$ was added to each well and the plate was incubated for $4 \mathrm{~h}$ at $37^{\circ} \mathrm{C}, 5 \% \mathrm{CO}_{2}$. Then, the MTT solution was removed, and $100 \mu \mathrm{l}$ dimethylsulfoxide was added to dissolve the colored formazan product. The intensity of the formazan product was measured at $570 \mathrm{~nm}$ using the microplate spectrophotometer (Bio-Rad Laboratories, Inc.). Each experiment was performed in triplicate. Results were reported in units of optical density (OD) and the relative growth rate was calculated using the following formula: Relative growth rate $(\%)=\left(\mathrm{OD}_{\text {treatment }} / \mathrm{OD}_{\text {control }}\right) \times 100$.

Cell cycle analysis. The cell cycle was analyzed with the aid of propidium iodide (PI) staining. HepG2 cells were seeded into 6-well plates at a density of $3 \times 10^{5}$ cells/well and exposed to SNP at various concentrations $(0,0.5,1.0$ and $1.5 \mathrm{mM})$ for $24 \mathrm{~h}$. They were then collected and washed with $0.01 \mathrm{M}$ ice-cold phosphate-buffered saline (PBS, pH 7.4) before fixing with $70 \%$ ethanol at $4{ }^{\circ} \mathrm{C}$ overnight. After washing and resuspending the fixed cells in $100 \mu \mathrm{l} \mathrm{PBS}$, they were treated with $100 \mu \mathrm{l}$ RNase A (DNase free, $100 \mu \mathrm{g} / \mathrm{ml}$; Solarbio Science $\&$ Technology Co., Ltd., Beijing, China) at $37^{\circ} \mathrm{C}$ for $30 \mathrm{~min}$ and stained with $400 \mu \mathrm{l}$ PI $(20 \mu \mathrm{g} / \mathrm{ml}$; Beyotime Institute of Biotechnology) in the dark at $4^{\circ} \mathrm{C}$ for $30 \mathrm{~min}$. The cell cycle was measured using a FACScan flow cytometer (BD FACSCalibur; BD Biosciences, San Jose, CA, USA). Each experiment was performed in triplicate.

Cell apoptosis assay. The apoptotic rate of the cells was detected by flow cytometry after staining with an Annexin V-fluorescein isothiocyanate (FITC) Apoptosis Detection kit (Beyotime Institute of Biotechnology). HepG2 cells $\left(5 \times 10^{4}\right.$ cells/well) were seeded into 6 -well plates and incubated with SNP $(0,0.5,1.0$ or $1.5 \mathrm{mM})$ for $24 \mathrm{~h}$. Subsequently, the cells from each sample were harvested and washed with PBS. Staining was conducted with $195 \mu 1$ Annexin V-FITC binding buffer, and $5 \mu 1$ Annexin V-FITC in the dark at room temperature for $10 \mathrm{~min}$. Each sample was then centrifuged at $445 \mathrm{xg}$ for $5 \mathrm{~min}$, resuspended in $190 \mu \mathrm{l}$ Annexin V-FITC binding buffer and $10 \mu \mathrm{l}$ PI was added. The samples were then analyzed using a FACScan flow cytometer, with $\geq 10,000$ events recorded for each sample. Each experiment was performed in triplicate.

Cell migration assay. Cell migration was determined using a wound healing assay. HepG2 cells were seeded at a density of $5 \times 10^{5}$ cells/well in 6 -well plates and incubated at $37^{\circ} \mathrm{C}$ for $24 \mathrm{~h}$. After that, a linear wound was created using a standard 1-ml pipette tip. Cells were washed with PBS to remove cell debris, cultured in serum-free DMEM medium and exposed to SNP $(0,0.5,1.0$ or $1.5 \mathrm{mM})$ for $24 \mathrm{~h}$. The wound spaces were imaged under a CK31 model inverted microscope (at x100 magnification; Olympus Corporation, Tokyo, Japan). Wound healing was analyzed using Image-Pro Plus software, version 6.0 (Media Cybernetics, Inc., Rockville, MD, USA), according to the following formula: Wound healing area $(\%)=$ [cell-free area $(0 \mathrm{~h})$ - cell-free area $(24 \mathrm{~h})] /$ cell-free area $(0 \mathrm{~h}) \times 100(11)$. Each experiment was performed in triplicate.

Cell invasion assay. Transwell plates (24-well insert, $8 \mu \mathrm{m}$ pore size; Corning Costar; Corning Incorporated, Lowell, MA, USA) were used to examine the ability of cells to invade through a Matrigel-coated filter following the protocol provided by the manufacturer. HepG2 cells were detached with trypsin (Wuhan Boster Bio-Engineering Co., Ltd.) and resuspended in serum-free DMEM medium. The lower chamber was filled with medium supplemented with $10 \%$ fetal calf serum as a chemoattractant, and $1 \times 10^{5}$ cells/well in $200 \mu \mathrm{l}$ serum-free DMEM medium were then seeded on the upper side of the chamber of the Transwell and incubated with $\operatorname{SNP}(0,0.5,1.0$ or $1.5 \mathrm{mM})$ for $24 \mathrm{~h}$. Following incubation, non-migrating cells on the upper chambers were removed with a cotton swab, and cells that had migrated to the lower side of the membrane were fixed with methanol and stained with $0.1 \%$ crystal violet. The membrane was visualized with an inverted microscope (at x200 magnification; Olympus Corporation). Invading cells were scored by counting at $\geq 5$ randomly selected fields per membrane, and expressed as the average number of cells/field of view. Each experiment was performed in triplicate.

Statistical analysis. All quantitative data are represented as mean \pm standard deviation. Statistical significance was analyzed by one-way analysis of variance followed by Newman-Keuls test. A P-value $<0.05$ was considered statistically significant. All statistical analyses were performed using SPSS software, version 17.0 (SPSS, Inc., Chicago, IL, USA) and GraphPad Prism, version 5.0 (GraphPad Software Inc., San Diego, CA, USA).

\section{Results}

Increased NO production in SNP-treated Hep G2 cell cultures. As shown in Fig. 1A, HepG2 cells treated with SNP (0.5, 1.0, 1.5 and $2.0 \mathrm{mM}$ ) for $24 \mathrm{~h}$ exhibited a significant increase in NO production compared with the control $(\mathrm{P}<0.05)$. The levels of NO in the control and SNP-treated $(0.5,1.0$ and $1.5 \mathrm{mM})$ groups were as follows: $18.17 \pm 3.40,47.67 \pm 2.52,75.27 \pm 4.61$ and $89.33 \pm 3.79 \mu \mathrm{mol} / 1$, respectively (Fig. 1A). However, no significant difference in NO production was observed between the 1.5 and $2.0 \mathrm{mM}$ groups $(89.33 \pm 3.79 \mathrm{vs} .94 .13 \pm 5.33 \mu \mathrm{mol} / 1$, 


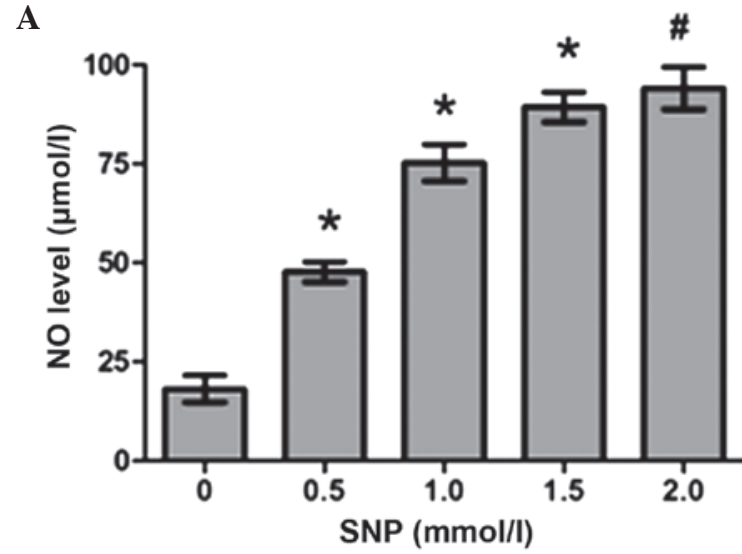

B

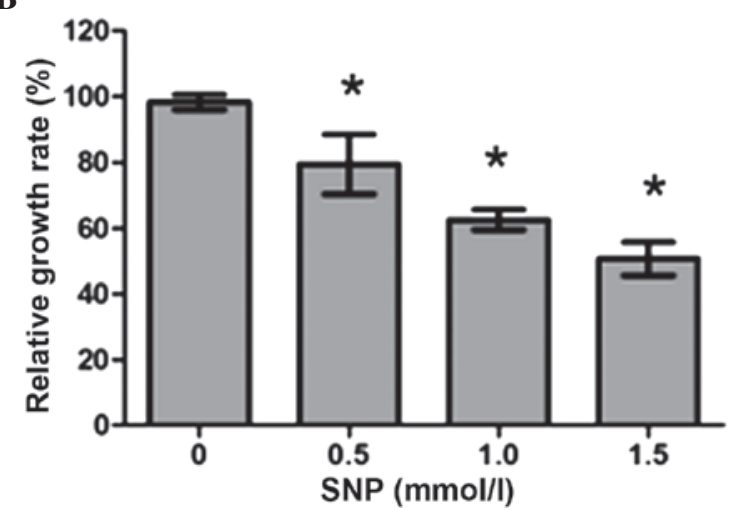

Figure 1. NO production and inhibitory effect of SNP on the viability of HepG2 cells. (A) NO levels in HepG2 cells following treatment with various SNP concentrations for $24 \mathrm{~h}$. (B) HepG2 cell viability following incubation with different concentrations of SNP for $24 \mathrm{~h}$, as detected by MTT assay. Data are presented as the mean \pm standard deviation from three independen experiments. ${ }^{*} \mathrm{P}<0.05$ vs. the un-treated control $(0 \mathrm{mmol} / \mathrm{l}),{ }^{"} \mathrm{P}>0.05$ vs. cells treated with $1.5 \mathrm{mmol} / 1 \mathrm{SNP}$. NO, nitric oxide;.SNP, sodium nitroprusside; MTT, methyl thiazolyl tetrazolium.

$\mathrm{P}>0.05$; Fig. 1A), indicating that the increase in $\mathrm{NO}$ production levels was not completely dependent upon SNP concentration in HepG 2 cultures.

Effect of NO on the viability of HepG2 cells. To assess whether NO regulates cell viability, HepG2 cells were incubated with various concentrations of $\operatorname{SNP}(0,0.5,1.0$ and $1.5 \mathrm{mM})$ for $24 \mathrm{~h}$ and an MTT assay was subsequently performed. The relative growth rates consistently decreased as the concentration of SNP increased, as shown in Fig. 1B; for 0, 0.5, 1.0 and $1.5 \mathrm{mM}$ SNP, the relative growth rates were $98.33 \pm 2.26$, $79.50 \pm 9.04,62.67 \pm 3.06$ and $50.81 \pm 5.02 \%$, respectively. For all concentrations of SNP, the difference in growth rate between the SNP-treated cells and the control was significant $(\mathrm{P}<0.05$; Fig. 1B). These data showed that NO clearly suppressed HepG2 cell proliferation in a concentration-dependent manner.

Effect of NO on the cell cycle of Hep 62 cells. A cell cycle assay was conducted to further examine the effect of NO on HepG2 cell growth. Following exposure to various concentrations of $\operatorname{SNP}(0,0.5,1.0$ and $1.5 \mathrm{mM})$ for $24 \mathrm{~h}$, the cell cycle was analyzed by flow cytometry. NO significantly increased the percentage of HepG 2 cells in the $G_{0} / G_{1}$ phase in a concentration-dependent manner; for $0,0.5,1.0$ and $1.5 \mathrm{mM}$ SNP, the percentage of cells in the $\mathrm{G}_{0} / \mathrm{G}_{1}$ phase was $38.22 \pm 1.49,51.82 \pm 1.83,57.55 \pm 1.58$ and $68.59 \pm 1.27 \%$, respectively $(\mathrm{P}<0.05$; Fig. 2$)$. This was accompanied by a reduction in the percentage of cells in the $\mathrm{G}_{2} / \mathrm{M}$ phase; for $0,0.5,1.0$ and $1.5 \mathrm{mM} \mathrm{SNP}$, the percentage in the $\mathrm{G}_{2} / \mathrm{M}$ phase was $34.16 \pm 2.54,22.04 \pm 1.78,16.83 \pm 2.15$ and $11.47 \pm 1.20 \%$, respectively $(\mathrm{P}<0.05$; Fig. 2 ). The percentage of cells in the $\mathrm{S}$ phase remained unchanged following treatment with low concentrations of SNP; for $0,0.5$ and $1.0 \mathrm{mM}$ SNP, the percentage of cells in the $\mathrm{S}$ phase was $27.77 \pm 1.56$, $26.92 \pm 1.24$ and $26.37 \pm 0.99 \%$, respectively ( $P>0.05$; Fig. 2). However, HepG2 cells treated with $1.5 \mathrm{mM}$ SNP exhibited a marked reduction in the percentage in the $\mathrm{S}$ phase compared with the control (18.58 \pm 1.04 vs. $27.77 \pm 1.56 \%, \mathrm{P}<0.05$; Fig. 2). These results suggest that NO inhibited the proliferation of HepG 2 cells by inducing $\mathrm{G}_{0} / \mathrm{G}_{1}$ phase arrest.

NO induces apoptosis of HepG2 cells. To investigate whether the decreased viability observed following NO treatment was caused by increased apoptosis, HepG2 cells were cultivated in the presence of SNP $(0,0.5,1.0$ and $1.5 \mathrm{mM})$ for $24 \mathrm{~h}$, and then flow cytometric analysis was conducted to quantify the apoptotic HepG2 cells. Following treatment with 0, 0.5, 1.0 and $1.5 \mathrm{mM}$ SNP, the percentages of apoptotic cells were $4.25 \pm 1.26,14.12 \pm 2.49,23.78 \pm 4.13$ and $30.62 \pm 3.22 \%$, respectively, with significant differences in apoptosis between the SNP-treated and untreated cells $(\mathrm{P}<0.05$, Fig. 3$)$. The results revealed that NO induced apoptosis in HepG2 cells in a concentration-dependent manner.

Effect of NO on the cell migration of HepG2 cells. To explore whether NO affects the migration potential of HepG2 cells, cell migration was examined using a wound healing assay. The wound healing assay demonstrated that the migration ability of HepG2 cells incubated with SNP $(0.5,1.0$ and $1.5 \mathrm{mM})$ for $24 \mathrm{~h}$ was significantly impaired compared with that of the negative control ( $0 \mathrm{mM}$; all $\mathrm{P}<0.05$, Fig. 4$)$. Following treatment for $24 \mathrm{~h}$, the percentage of wound healing area was $86.59 \pm 3.75 \%$ for the negative control cells, $60.06 \pm 4.32 \%$ for the cells treated with $0.5 \mathrm{mM}$ SNP, $27.51 \pm 1.97 \%$ for the cells treated with $1.0 \mathrm{mM} \mathrm{SNP}$ and $14.45 \pm 2.49 \%$ for the cells treated with $1.5 \mathrm{mM}$ SNP (Fig. 4). This indicates that the migration capacity of HepG2 cells was inhibited by NO.

Effect of NO on the invasion of Hep 2 cells. The invasion ability of HepG2 cells treated with SNP $(0,0.5,1.0$ and $1.5 \mathrm{mM}$ ) for $24 \mathrm{~h}$ was also examined using a Transwell assay. The numbers of invading cells in the control group and the SNP-treated groups $(0.5,1.0$ and $1.5 \mathrm{mM})$ were as follows: $112.0 \pm 13.11,80.25 \pm 8.65,24.47 \pm 6.91$ and $11.30 \pm 2.79$, respectively. For all concentrations of SNP, the difference in the number of invading cells between the SNP-treated cells and the control was significant $(\mathrm{P}<0.05$, Fig. 5). The results of the Transwell chamber assay showed that NO inhibited cell invasion in a concentration-dependent manner.

\section{Discussion}

$\mathrm{NO}$ is known to be involved in diverse processes in numerous physiological and pathophysiological conditions; previous studies have suggested that NO can exert a negative effect on the 
A
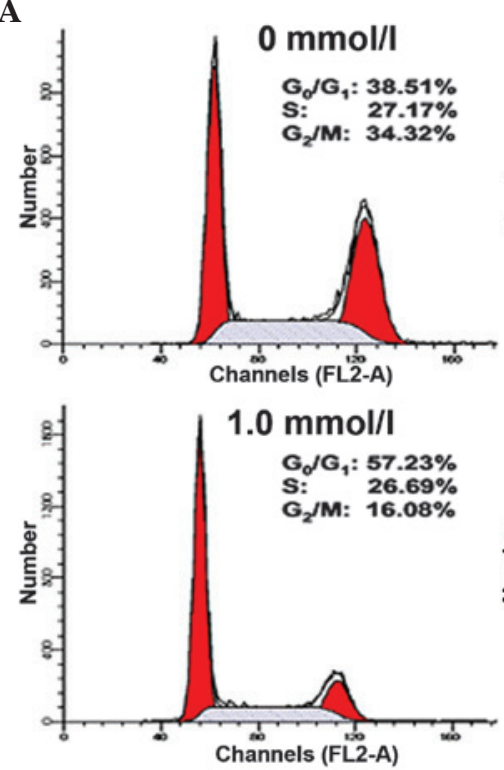
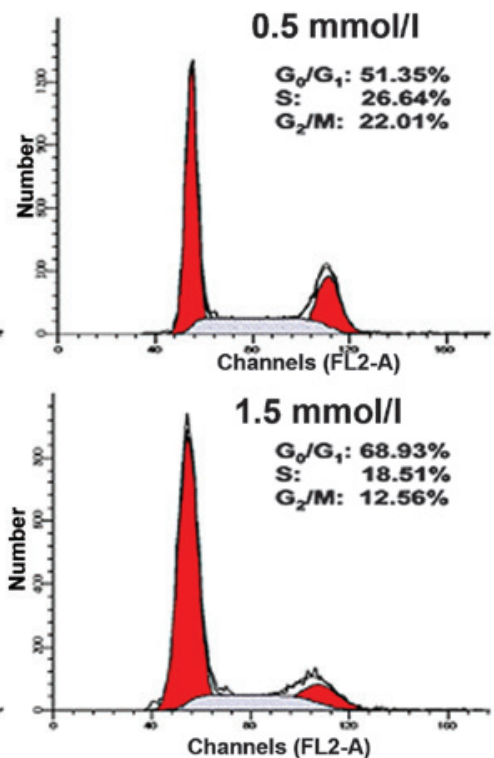

B
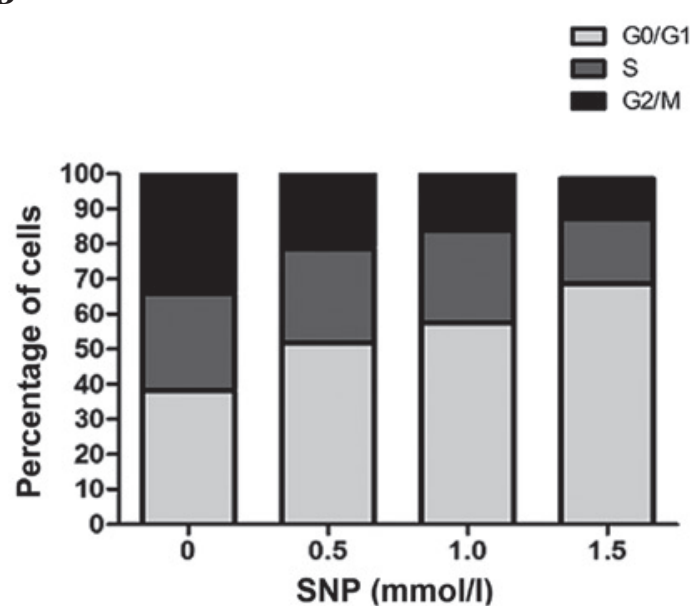

Figure 2. SNP induced cell cycle arrest in HepG2 cells. (A) Representative results of cell cycle analysis for HepG2 cells treated with various concentrations of SNP for $24 \mathrm{~h}$ and assessed using PI staining. (B) Statistical analysis of the percentage of cells in the $\mathrm{G}_{0} / \mathrm{G}_{1}, \mathrm{~S}$ and $\mathrm{G}_{2} / \mathrm{M}_{\mathrm{phases}}$ of the cell cycle. SNP, sodium nitroprusside; PI, propidium iodide.
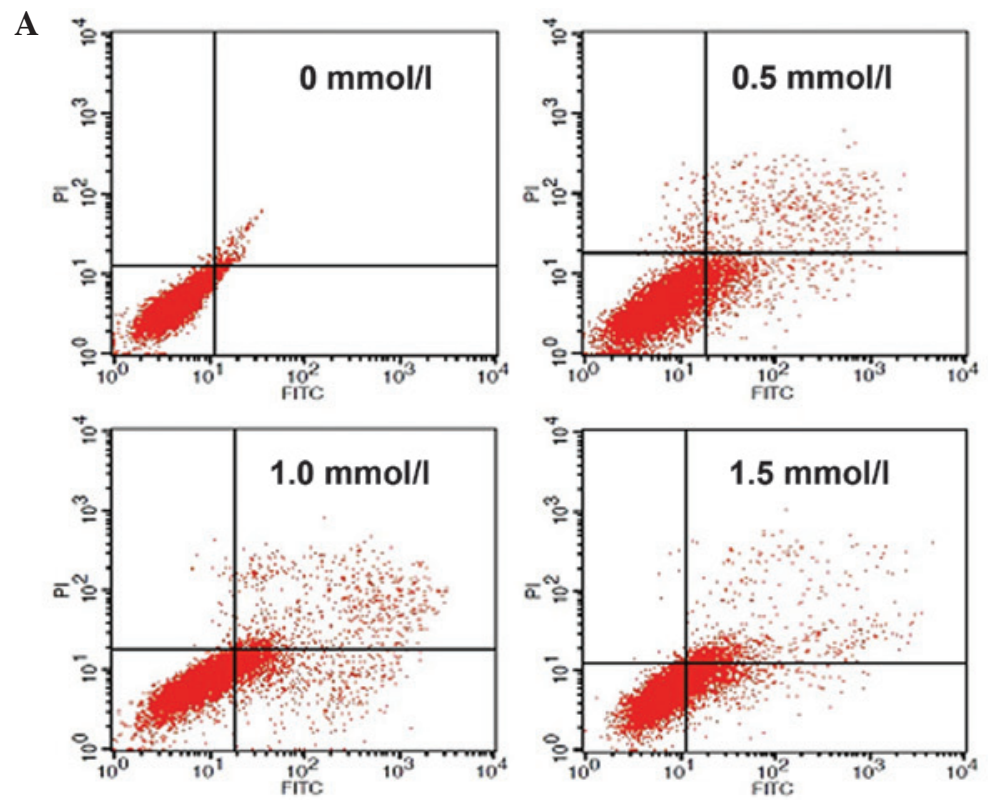

$\mathbf{B}$

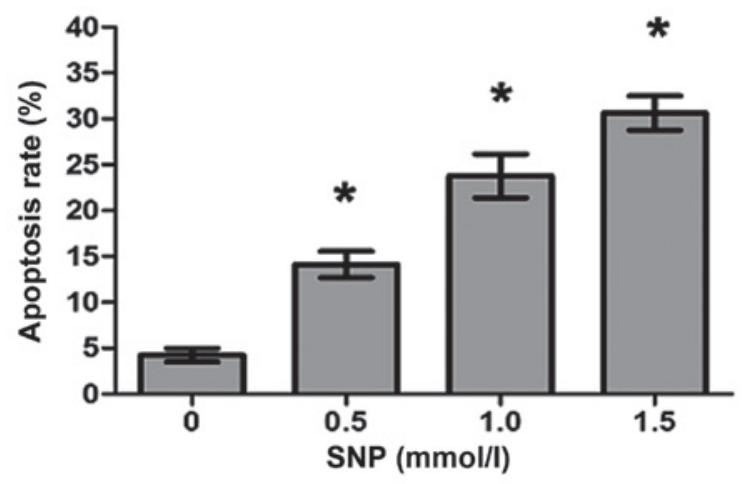

Figure 3. SNP induced apoptosis in HepG2 cells. (A) Representative results of an apoptosis assay for HepG2 cells treated with various concentrations of SNP for $24 \mathrm{~h}$, with assessment using Annexin V-FITC/PI double staining. (B) Statistical analysis of the apoptosis rates in HepG2 cells treated with various concentrations of SNP. Data presented are the mean \pm standard deviation from three independent experiments. $\mathrm{P}<0.05$ vs. the un-treated control $(0 \mathrm{mmol} / \mathrm{l})$. SNP, sodium nitroprusside; FITC, fluorescein isothiocyanate; PI, propidium iodide

regulation of tumor cell behavior and an anti-neoplastic effect in vivo and in vitro (10,12-18). However, studies concerning the effects of NO on HCC cells are rare. In the present study, the effects of chemically derived NO on the biological behavior of the human hepatocellular carcinoma cell line HepG2 were investigated.

The typical characteristics of tumor cell proliferation are out-of-control cell division and excessive growth. Therefore, inhibiting tumor cell proliferation is an important aspect of the control of tumorigenesis. In the present study, the effect of NO on the proliferation of HepG2 cells was evaluated. As shown in Fig. 1B, the proliferation of HepG2 cells was significantly inhibited by NO, with a greater degree of suppression when increasing concentrations of SNP were used. This observation is consistent with a previous study, which demonstrated that NO generated by treatment with SNP inhibited the cell proliferation of gastric cancer cells in a concentration-dependent manner (16).

In eukaryotic cells, cell cycle checkpoints are regulatory pathways that control the order and timing of cell cycle 

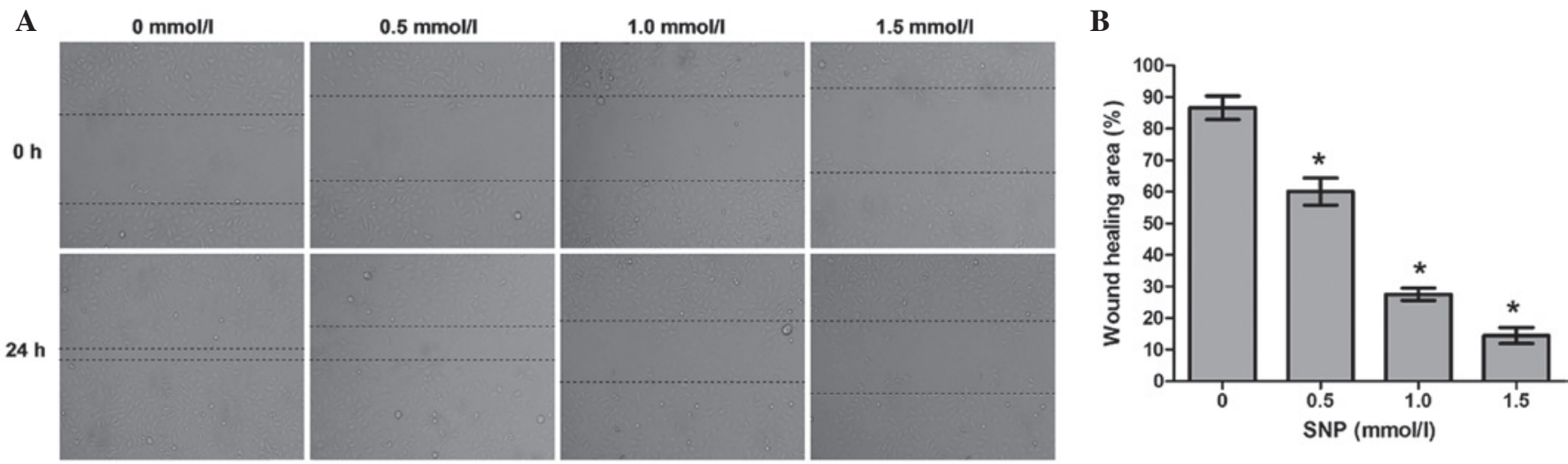

Figure 4. SNP inhibited HepG2 cell migration in a wound healing assay. (A) Migration of HepG2 cells was photographed under a light microscope following treatment with various concentrations of SNP for $24 \mathrm{~h}$. Results from a representative experiment are shown (magnification, x100). (B) Statistical analysis of the wound healing area in HepG2 cells treated with various concentrations of SNP. Data presented are the mean \pm standard deviation from three independent experiments. ${ }^{*} \mathrm{P}<0.05$ vs. the untreated control $(0 \mathrm{mmol} / \mathrm{l})$. SNP, sodium nitroprusside.

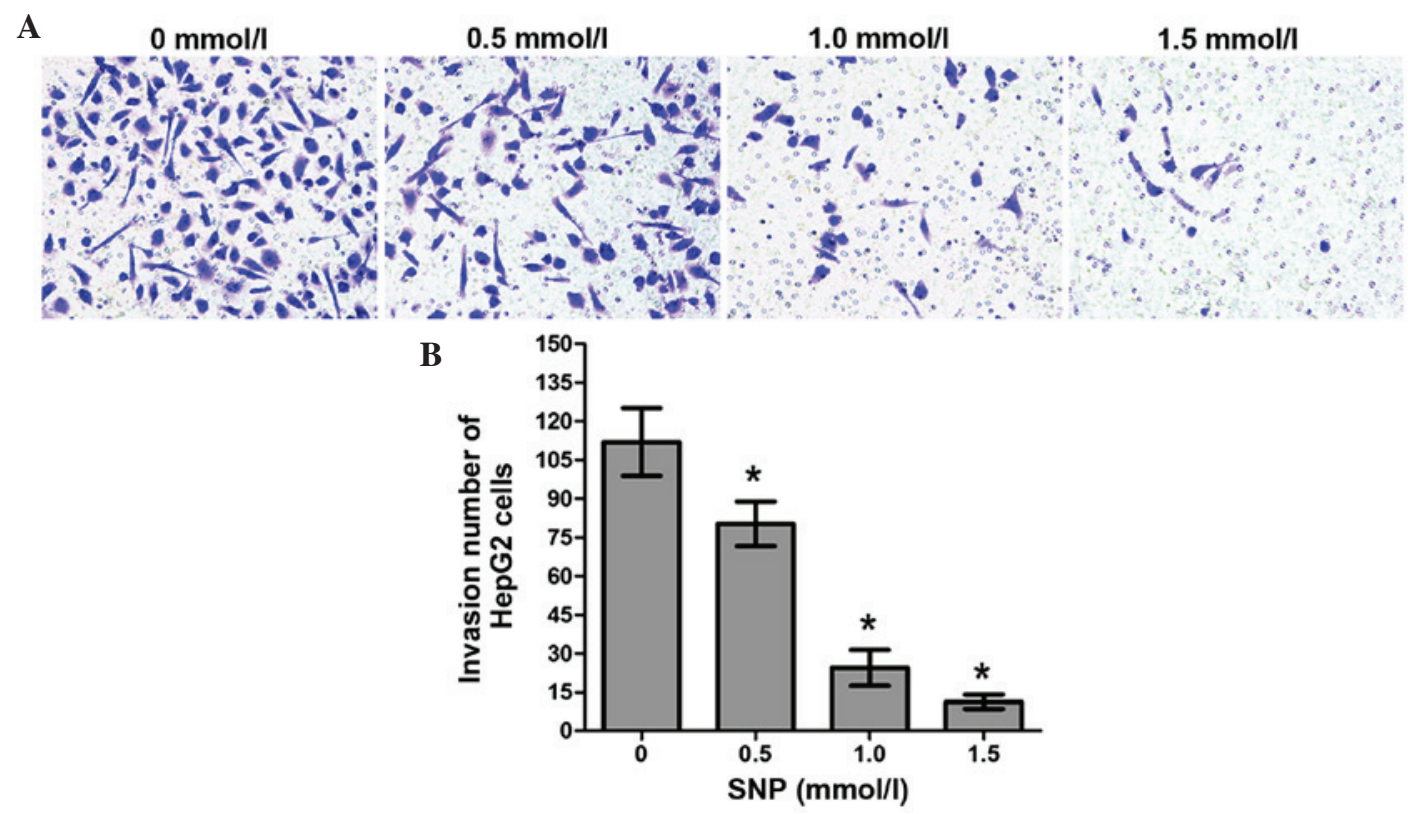

Figure 5. SNP inhibited HepG2 cell invasion in the Matrigel invasion assay. (A) HepG2 cells were treated with various concentrations of SNP for $24 \mathrm{~h}$ and the invading cells were photographed under a light microscope. Results from a representative experiment are shown (magnification, x200). (B) Statistical analysis of number of invading HepG2 cells treated with various concentrations of SNP. Data presented are the mean \pm standard deviation from three independent experiments. "P<0.05 vs. the untreated control $(0 \mathrm{mmol} / \mathrm{l})$.

transitions and ensure that critical events, such as DNA replication and chromosome segregation, are completed (19). During the cell cycle, the regulation of cells transformation from the $G_{1}$ phase into the $S$ phase is particularly important, as the $\mathrm{G}_{1}-\mathrm{S}$ checkpoint allows for the replication of DNA (20). In the present study, cell cycle analysis revealed that in SNP-treated HepG2 cells, a significant increase in the proportion of $\mathrm{G}_{0} / \mathrm{G}_{1}$ phase cells occurred, accompanied by a reduction in the proportion of $\mathrm{G}_{2} / \mathrm{M}$ phase cells. These data indicate that $\mathrm{NO}$ arrested HepG2 cells in the $\mathrm{G}_{1}$ phase. Sang et al observed that SNP-derived NO inhibited the proliferation of gastric cancer cells by blocking the conversion from the $G_{1}$ to the $S$ phase, and the $G_{1}$ arrest was mediated through the regulation of cell cycle-related proteins, which was likely to be associated with the inactivation of Akt signaling (16). These results suggest that NO can regulate cell cycle transition, thereby suppressing cancer cell proliferation.

Apoptosis is programmed cell death that plays a major role during developmental processes and is circumvented during the malignant transformation and progression of tumors $(21,22)$. The induction of apoptosis is a common mechanism underlying the cytotoxic effects of anticancer agents, in addition to cell cycle arrest $(23,24)$. In addition to cell proliferation, apoptosis in NO-treated HepG2 cells was investigated in the present study. The results indicated that NO induced cell apoptosis in a concentration-dependent manner. Previously, SNP-derived NO has exhibited potent pro-apoptotic effects on lung carcinoma cells and cutaneous T cell lymphoma cells $(13,14)$. The induction of apoptosis by NO involves downregulation of the expression of survivin, 
constitutive nuclear factor- $\kappa \mathrm{B}$ and $\mathrm{B}$-cell lymphoma-extra large (Bcl-xL) $(13,14)$.

Metastasis is a typical characteristic of HCC, including intrahepatic metastasis and metastasis to extrahepatic organs (25). Tumor metastasis involves a series of interrelated events; cell migration and invasion are two critical steps. In our previous study, it was noted that the level of NO was higher in HCC tissues without metastasis than those with metastasis (10). This implied that NO could partially inhibit the metastatic cascade in HCC. Therefore, the effect of NO on the migration and invasion of HepG2 cells was examined in the present study using a wound healing assay and a Transwell invasion assay. The results showed that NO significantly inhibited cell migration and invasion in a concentration-dependent manner in vitro. These results were concordant with those of other studies, in which it was observed that NO suppressed migration and invasion in different tumor cell lines, and the anti-metastasis effects were shown to be associated with the upregulation of $\mathrm{N}-\mathrm{Myc}$ downstream-regulated gene 1 (NDRG1), inhibition of hypoxia-inducible factor 1 (HIF-1) and impairment of mitochondria $(17,26)$. However, this is in contrast to another study, which demonstrated that long-term (7 or 14 day) treatment with NO significantly increased the migratory action of human lung cancer cells through increased expression of caveolin-1 (Cav-1) and cell division cycle 42 (Cdc42) proteins (27). These conflicting results could be explained by the observation that the final activity of $\mathrm{NO}$ in oncology is dependent upon its working microenvironment, including the type of cell exposed to the compound, the redox state of the reaction, as well as the final intracellular concentration and the duration of intracellular exposure to NO (5).

In conclusion, the present study indicated that NO effectively suppressed proliferation, migration and invasion, arrested the cell cycle and induced apoptosis in HepG2 cells; however, the detailed mechanism underlying these effects is unclear. Further investigation is required to identify cellular targets of NO and the precise molecular mechanism of action underlying the effects of NO in HepG2 cells, with the aim of preventing and treating $\mathrm{HCC}$ with $\mathrm{NO}$.

\section{Acknowledgements}

This study was supported by a starting fund from The Central Hospital of Wuhan (grant no. YQ13B06).

\section{References}

1. El-Serag HB and Rudolph KL: Hepatocellular carcinoma: Epidemiology and molecular carcinogenesis. Gastroenterology 132: 2557-2576, 2007.

2. International Agency for Research on Cancer: Cancer incidence and mortality worldwide: sources, methods and major patterns in GLOBOCAN 2012. http://www-dep.iarc.fr/. Accessed August 10, 2014.

3. Imamura H, Matsuyama Y, Tanaka E, Ohkubo T, Hasegawa K, Miyagawa S, Sugawara Y, Minagawa M, Takayama T, Kawasaki S, et al: Risk factors contributing to early and late phase intrahepatic recurrence of hepatocellular carcinoma after hepatectomy. J Hepatol 38: 200-207, 2003.

4. Kamiyama T, Nakanishi K, Yokoo H, Kamachi H, Tahara M, Suzuki T, Shimamura T, Furukawa H, Matsushita M, Todo S, et al: Recurrence patterns after hepatectomy of hepatocellular carcinoma: implication of Milan criteria utilization. Ann Surg Oncol 16: 1560-1571, 2009.
5. Huerta S, Chilka S and Bonavida B: Nitric oxide donors: Novel cancer therapeutics (review). Int J Oncol 33: 909-927, 2008

6. Thomsen LL, Miles DW, Happerfield L, Bobrow LG, Knowles RG and Moncada S: Nitric oxide synthase activity in human breast cancer. Br J Cancer 72: 41-44, 1995.

7. Ambs S, Merriam WG, Bennett WP, Felley-Bosco E, Ogunfusika MO, Ose SM, Klein S, Shields PG, Billiar TR and Harris CC: Frequent nitric oxide synthase-2 expression in human colon adenomas: Implication for tumor angiogenesis and colon cancer progression. Cancer Res 58: 334-341, 1998.

8. Ekmekcioglu S, Ellerhorst J, Smid CM, Prieto VG, Munsell M, Buzaid AC and Grimm EA: Inducible nitric oxide synthase and nitrotyrosine in human metastatic melanoma tumors correlate with poor survival. Clin Cancer Res 6: 4768-4775, 2000.

9. Masri FA, Comhair SA, Koeck T, Xu W, Janocha A, Ghosh S, Dweik RA, Golish J, Kinter M, Stuehr DJ, et al: Abnormalities in nitric oxide and its derivatives in lung cancer. Am J Respir Crit Care Med 172: 597-605, 2005.

10. Zhou L, Wang Y, Tian DA, Yang J and Yang YZ: Decreased levels of nitric oxide production and nitric oxide synthase-2 expression are associated with the development and metastasis of hepatocellular carcinoma. Mol Med Rep 6: 1261-1266, 2012.

11. Hu J and Verkman AS: Increased migration and metastatic potential of tumor cells expressing aquaporin water channels. FASEB J 20: 1892-1894, 2006.

12. Hussain SP, Trivers GE, Hofseth LJ, He P, Shaikh I, Mechanic LE, Doja S, Jiang W, Subleski J, Shorts L, et al: Nitric oxide, a mediator of inflammation, suppresses tumorigenesis. Cancer Res 64: 6849-6853, 2004.

13. Chao JI, Kuo PC and Hsu TS: Down-regulation of survivin in nitric oxide-induced cell growth inhibition and apoptosis of the human lung carcinoma cells. J Biol Chem 279: 20267-20276, 2004.

14. Rishi L, Dhiman R, Raje M and Majumdar S: Nitric oxide induces apoptosis in cutaneous T cell lymphoma (HuT-78) by downregulating constitutive NF-kappaB. Biochim Biophys Acta 1770: 1230-1239, 2007.

15. Bonavida B, Baritaki S, Huerta-Yepez S, Vega MI, Chatterjee D and Yeung K: Novel therapeutic applications of nitric oxide donors in cancer: Roles in chemo-and immunosensitization to apoptosis and inhibition of metastases. Nitric Oxide 19: 152-157, 2008.

16. Sang J, Chen Y and Tao Y: Nitric oxide inhibits gastric cancer cell growth through the modulation of the Akt pathway. Mol Med Rep 4: 1163-1167, 2011.

17. Hickok JR, Sahni S, Mikhed Y, Bonini MG and Thomas DD: Nitric oxide suppresses tumor cell migration through N-Myc downstream-regulated gene-1 (NDRG1) expression: Role of chelatable iron. J Biol Chem 286: 41413-41424, 2011.

18. Bonavida B and Baritaki S: Dual role of NO donors in the reversal of tumor cell resistance and EMT: Downregulation of the NF-kB/Snail/YY1/RKIP circuitry. Nitric Oxide 24: 1-7, 2011.

19. Elledge SJ: Cell cycle checkpoints: Preventing an identity crisis. Science 274: 1664-1672, 1996.

20. Wang Y, Ji P, Liu J, Broaddus RR, Xue F and Zhang W: Centrosome-associated regulators of the $\mathrm{G}(2) / \mathrm{M}$ checkpoint as targets for cancer therapy. Mol Cancer 13: 8, 2009.

21. Jacobson MD, Weil M and Raff MC: Programmed cell death in animal development. Cell 88: 347-354, 1997

22. Onishi Y, Ueha T, Kawamoto T, Hara H, Toda M, Harada R, Minoda M, Kurosaka M and Akisue T: Regulation of mitochondrial proliferation by PGC-1 $\alpha$ induces cellular apoptosis in musculoskeletal malignancies. Sci Rep 4: 3916, 2014.

23. Sun SY, Hail N Jr and Lotan R: Apoptosis as a novel target for cancer chemoprevention. J Natl Cancer Inst 96: 662-672, 2004.

24. Yin X, Zhang J, Li X, Liu D, Feng C, Liang R, Zhuang K, Cai C, Xue X, Jing $F$, et al: DADS suppresses human esophageal xenograft tumors through RAF/MEK/ERK and mitochondria-dependent pathways. Int J Mol Sci 15: 12422-12441, 2014.

25. Tang ZY: Hepatocellular carcinoma-cause, treatment and metastasis. World J Gastroenterol 7: 445-454, 2001.

26. Wang F, Zhang R, Xia T, Hsu E, Cai Y, Gu Z and Hankinson O: Inhibitory effects of nitric oxide on invasion of human cancer cells. Cancer Lett 257: 274-282, 2007.

27. Sanuphan A, Chunhacha P, Pongrakhananon V and Chanvorachote P: Long-term nitric oxide exposure enhances lung cancer cell migration. Biomed Res Int 2013: 186972, 2013. 